\title{
Antenatal Glucocorticoid Corrects Pulmonary Immaturity in Experimentally Induced Congenital Diaphragmatic Hernia in Rats
}

\author{
HON CHI SUEN, KENNETH D. BLOCH, AND PATRICIA K. DONAHOE \\ Pediatric Surgical Research Lahoratories, Pediatric Surgical Services, General Thoracic Surgical Unit, and \\ Cardiac Unit, Medical Services, Massachusetts General Hospital, Boston, Massachusetts 02114, and the \\ Departments of Surgery and Medicine, Harvard Medical School, Boston, Massachusetts 02115
}

\begin{abstract}
Congenital diaphragmatic hernia, a highly lethal condition, displays at term the pulmonary biochemical and morphologic immaturity characteristic of premature delivery. We hypothesized that antenatal glucocorticoid, now the standard treatment to prevent hyaline membrane disease in premature human beings, might correct the parameters of the pulmonary biochemical and morphologic immaturity in severe congenital diaphragmatic hernia. A total of 112 fetal rats with or without nitrofen-induced congenital diaphragmatic hernias from 34 pregnancies were treated antenatally with either saline or dexamethasone. Antenatal dexamethasone increased the lung disaturated phosphatidylcholine content, reduced the lung glycogen concentration, reduced the saccular septal thickness, and increased the mean saccular size and volume fraction of saccules in the lungs of rats with large congenital diaphragmatic hernia in comparison with similar rats not so treated. All differences were statistically significant. Antenatal glucocorticoid therapy was efficacious in treating rats with nitrofen-induced congenital diaphragmatic hernia. This encouraging finding warrants further investigation in a large animal model with surgically created congenital diaphragmatic hernia. (Pediatr Res 35: 523-529, 1994)
\end{abstract}

\section{Abbreviations}

CDH, congenital diaphragmatic hernia non-CDII, noncongenital diaphragmatic hernia DSPC, disaturated phosphatidylcholine i.p., intraperitoneally RNase, ribonuclease ET1, endothelin 1

$\mathrm{CDH}$ occurs when the pleuroperitoneal septum fails to separate the thoracic and abdominal cavities; it results in death for many affected infants despite the introduction of novel interventional therapies in conjunction with improved neonatal intensive care $(1,2)$. Death of infants with $\mathrm{CDH}$ is associated with profound pulmonary hypoplasia (3-5) and persistent pulmonary hypertension (6). Convincing evidence has accumulated that the neonatal lung in the presence of lethal $\mathrm{CDH}$ is both biochemically and morphologically immature. Blackburn et al. (7) in 1977 and Wigglesworth et al. (8) in 1981 showed that CDH lungs had significantly reduced lecithin (phosphatidylcholine) content and

Received March 22, 1993: accepted December 9, 1993.

Correspondence and reprint requests: Patricia K. Donahoe. M.D., Pediatric Surgical Services, Massachusetts General Hospital, Fruit St., Boston, MA 02114.

Supported by grants from the Department of Surgery, Massachusetts General Hospital (P.K.D.) and NHLBI HL 45895 (K.D.B.). a smaller number of lamellar granules in type II pneumocytes; furthermore, the lecithin/sphingomyelin ratio was reduced and phosphatidylglycerol was absent in the amniotic fluid surrounding these otherwise normal full-term fetuses $(9,10)$, although others have observed more normal ratios $(11,12)$. George $c t$ al. (13) documented that lungs from 10 neonates dying of $\mathrm{CDH}$ (seven of them full term) were morphologically immature for their gestational age.

Antenatal maternal administration of glucocorticoids is an established therapy well known for diminishing the severity of hyaline membrane disease in premature babies $(14,15)$. Its observed propitious effects on the lung include the accelerated appearance, accumulation, and secretion of surfactant (16-18); a reduction of mesenchymal volume and narrowing of alveolar septal thickness (19); an increase in maximal lung volume (20) and compliance (21); and an increase of antioxidant enzyme activities in the fetal lung (22), leading to decreased incidence, severity, and deaths resulting from neonatal respiratory distress syndrome associated with premature delivery $(14,15)$.

We recently reported that neonatal rat lungs in the presence of large $\mathrm{CDH}$ created experimentally by maternal feeding of nitrofen (2,4-dichloro-4'-nitrodiphenyl ether) were biochemically and morphologically immature, as manifested by smaller, atelectatic lungs with diminished DSPC and a higher glycogen content (23). We used this relatively inexpensive, short-gestation, small-animal model to study whether treatment of these animals with antenatal dexamethasone could significantly improve important parameters of pulmonary maturity. The experimental findings of this study indicate that the lungs in full-term human neonates with severe $\mathrm{CDH}$, which are known to display similar biochemical and morphologic characteristics of prematurity, might respond to prenatal glucocorticoid therapy and thus improve their dismal outcome. Further studies in large non-nitrofen-treated animals will be needed to confirm these findings.

\section{MATERIALS AND METHODS}

The experimental design is outlined in Figure 1. Timed pregnant Sprague-Dawley rat mothers (Holtzman Laboratories, Madison, WI; vaginal smear positive, d 0 ; term, d 22), briefly anesthetized with ether on $\mathrm{d} 9.5$ of gestation, were tube fed $100 \mathrm{mg}$ of nitrofen (technical grade, 92\% purity, Zhejiang Chemicals Import and Export Corporation, China) dissolved in $2 \mathrm{~mL}$ of olive oil to create $\mathrm{CDH}$ in a proportion of neonatal rats. This treatment and subsequent animal care were carried out in accordance with institutional guidelines (MGH Accession 924124). Some mothers (treated) were injected with dexamethasone before delivery, and others (untreated) were injected with saline or not injected at all. The dams were killed on d 21.5 of gestation, and fetuses were delivered by cesarean section. Pups with diaphragmatic hernias occupying more than $50 \%$ of the thoracic 


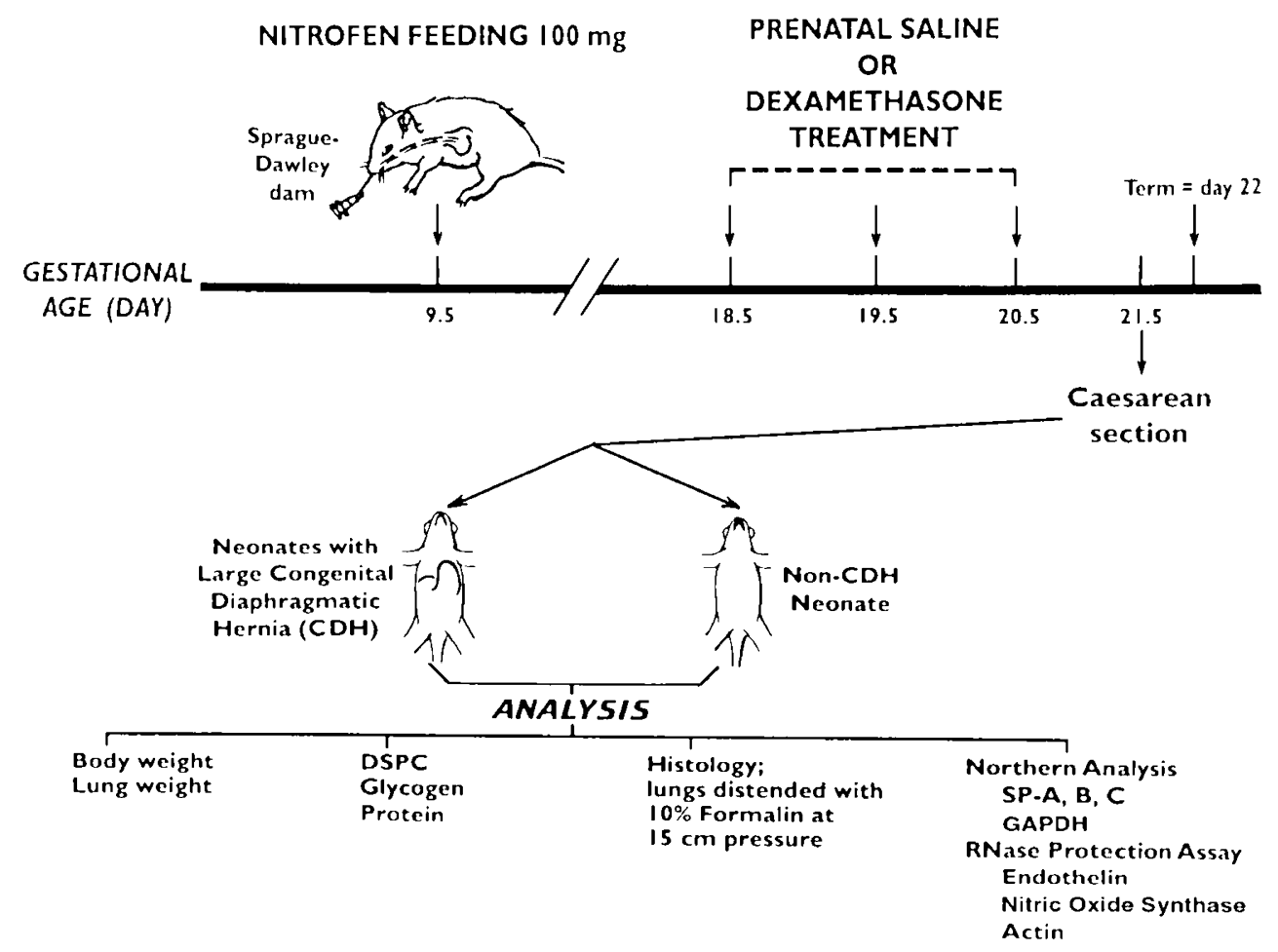

Fig. 1. Experimental design.

cavity were designated $\mathrm{CDH}$ rats, and pups without diaphragmatic hernias were designated non-CDH rats. All CDH rats were studied. Because non-CDH rats always outnumbered $\mathrm{CDH}$ rats, only a similar number of non-CDH rats from each pregnancy were randomly chosen for subsequent analysis. Pups with diaphragmatic hernias occupying less than $50 \%$ of the thoracic cavity were not analyzed so that a uniform degree of pulmonary hypoplasia among the analyzed $\mathrm{CDH}$ rats could be maintained. Comparisons between treated and untreated rats were performed with biochemical, morphologic, and molecular methods. Three dosages of dexamethasone were tested in the biochemical analyses. Because dexamethasone produced greater reduction of birth weight and lung weight in both the CDH and non-CDH rats, the lowest of the three dosages of dexamethasone that resulted in significant biochemical improvement but the least inhibition of somatic and pulmonary growth was used in the morphometrical and molecular experiments.

Biochemical analyses. To study biochemical differences, we gave animals three different dosages of dexamethasone (Gensia, Irvine, $\mathrm{CA}$ ): $0.25 \mathrm{mg} / \mathrm{kg}$ i.p. on d 18.5 and $19.5(n=2 \mathrm{dams})$; $0.25 \mathrm{mg} / \mathrm{kg}$ ip on $\mathrm{d} 18.5,19.5$, and $20.5(n=3 \mathrm{dams})$; and 1 $\mathrm{mg} / \mathrm{kg}$ i.p. on d $18.5,19.5$, and $20.5(n=3$ dams $)$. The dose schedule of $0.25 \mathrm{mg} / \mathrm{kg}$ for $3 \mathrm{~d}$ was chosen because it approximates doses currently used in human pregnancy to hasten maturation of fetal lungs (24). The lower and higher doses were chosen empirically to study the dose-related response. The pups of five pregnant dams served as controls, with three dams uninjected and two injected with $0.15 \mathrm{~mL}$ (the volume of dexamethasone used in the treated groups) of normal saline i.p. on $\mathrm{d} 18.5$, 19.5, and 20.5. On d 21.5, 132 neonatal rats were delivered and their birth weights recorded. There were $30 \mathrm{CDH}$ rats $(24$ leftsided and six right-sided); all were subsequently analyzed. Thirtyfive non-CDH rats were randomly selected from a pool of 92 for subsequent analysis. Ten other rats with only small $\mathrm{CDH}$ were excluded. Lungs from nine neonatal rats whose mother was fed olive oil only without nitrofen were also assayed for comparison to understand the effect of nitrofen on lung development. The number of rats used in each treatment group is shown in Figure $2 A$.

Each heart-lung block was removed from the chest, and the lungs were cleared of surrounding parenchyma, frozen in liquid nitrogen, and stored at $-80^{\circ} \mathrm{C}$. Lungs at the time of assay were weighed and homogenized (Polytron, Brinkmann Instruments, Westbury, NY) on ice after adding 19 volumes of distilled water to create a 20-fold dilution (assuming lung density of $1 \mathrm{~g} / \mathrm{mL}$ ). Six smaller lungs (three $\mathrm{CDH}$ and three non-CDH lungs) were diluted 30-fold. Lung homogenates were assayed for DSPC, protein, and glycogen content as previously reported (23). Briefly, to assay for DSPC, we extracted lipid on $0.15 \mathrm{~mL}$ of the homogenate with a chloroform-methanol 2:1 (vol/vol) mixture. After centrifugation, the supernatant was washed with $0.1 \mathrm{M}$ potassium chloride solution according to Folch et al. (25). After the upper phase was removed, the lower phase was evaporated to dryness with dry nitrogen gas. The lipid extract was reacted with osmium tetroxide, evaporated again, and the residue dissolved in chloroform-methanol 20:1 ( $\mathrm{vol} / \mathrm{vol})$. DSPC was isolated through an activated neutral alumina column after elution by chloroformmethanol-7M ammonium hydroxide 70:30:2 (vol/vol/vol) (26). The amount of DSPC was determined by assaying the phosphorus content in the eluent by the method of Bartlett (27).

Glycogen was measured by the method of Lo et al. (28); 0.5 $\mathrm{mL}$ of the lung homogenate was digested with $30 \%$ potassium hydroxide saturated with sodium sulfate and precipitated with $95 \%$ ethanol. The glycogen precipitate was redissolved in water and the amount of glycogen determined by the phenol-sulfuric acid color reaction. Protein was determined by the method of Bradford (29).

Morphometrical analysis. For morphometrical analysis, pup lungs from six dexamethasone-treated $(0.25 \mathrm{mg} / \mathrm{kg}$ i.p., d 18.5 and 19.5) and five untreated (saline-injected on the same days) dams were collected on $\mathrm{d} 21.5$ by cesarean section. Before delivery from the uterus, each pup was given an i.p. injection of $6.5 \mathrm{mg}$ pentobarbital to prevent subsequent insufflation by breathing air. After delivery, the trachea was cannulated and the lungs distended in situ with the chest open at $15-\mathrm{cm}$ pressure with $10 \%$ formalin. Each trachea was then ligated to maintain the lungs in standardized inflation during fixation. Midcoronal paraffin sections $(8 \mu \mathrm{m})$ stained with hematoxylin and eosin were studied stereologically with a Nikon Diaphot inverted microscope (Nikon, Garden City, NY) equipped with a $10 \times$ objective 
with lung maturation (38). Among the $\mathrm{CDH}$ rats, the mean lung glycogen concentrations were significantly decreased by antenatal dexamethasone treatment at doses of $0.25 \mathrm{mg} / \mathrm{kg}$ i.p. for $3 \mathrm{~d}$ $(0.108 \pm 0.023 \mathrm{mg} / \mathrm{mg}$ protein, $p=0.042)$ and at doses of $1 \mathrm{mg} /$ $\mathrm{kg}$ i.p. for $3 \mathrm{~d}(0.115 \pm 0.008 \mathrm{mg} / \mathrm{mg}$ protein, $p=0.01)$ but not at doses of $0.025 \mathrm{mg} / \mathrm{kg}$ i.p. for $2 \mathrm{~d}(0.142 \pm 0.014 \mathrm{mg} / \mathrm{mg}$ protein, $p=0.494$ ) when compared with the CDH rats not treated with dexamethasone $(0.153 \pm 0.008 \mathrm{mg} / \mathrm{mg}$ protein) (Fig. $2 B$ ). The effects of dexamethasone on the nitrofen non-CDH rats were also apparent. Without dexamethasone treatment, no statistical significant difference was observed in the lung glycogen mean concentrations among the olive oil $(0.163 \pm 0.01 \mathrm{mg} / \mathrm{mg}$ protein), nitrofen non-CDH $(0.139 \pm 0.012 \mathrm{mg} / \mathrm{mg}$ protein), and nitrofen $\mathrm{CDH}(0.153 \pm 0.008 \mathrm{mg} / \mathrm{mg}$ protein) groups. Nitrofen administration decreased birth weight and lung weight, and dexamethasone further reduced these two parameters in a dose-related manner in both the $\mathrm{CDH}$ and non-CDH rats (Fig. 3).

Morphologically, lungs in the untreated $C D H$ rats have smaller saccules and thicker saccular septal walls compared with untreated non-CDH rats, whereas antenatal dexamethasone enlarged the pulmonary saccules and decreased the saccular septal wall thickness in the lungs of rats with large CDH (Fig. 4). The mean saccular volume of the untreated CDH rats $(93200 \pm$ $18400 \mu \mathrm{m}^{3}$ ), which was much smaller than that of the untreated non-CDH rats $\left(275000 \pm 17000 \mu \mathrm{m}^{3}, p<0.001\right)$, was significantly increased by dexamethasone treatment $(148000 \pm 17300$ $\mu \mathrm{m}^{3}, p=0.03$, Fig. $5 A$ and $\left.B\right)$. The volume fraction of saccules in the lung of the untreated $\mathrm{CDH}$ rats $(0.24 \pm 0.01)$, which was much smaller than that of the untreated non-CDH rats $(0.4 \pm$ $0.001)$, was also increased by dexamethasone treatment $(0.3 \pm$ $0.02, p=0.007$, Fig. 5.4 and $C$ ).

No significant differences were seen in the pulmonary SP-A, SP-B, SP-C (Fig. 6), ET1 (Fig. 7), and endothelial nitric oxide synthase (Fig. 8) mRNA concentrations measured for wholelung extracts between the untreated $\mathrm{CDH}$ and untreated non$\mathrm{CDH}$ rats fed nitrofen. After antenatal dexamethasone treatment

A

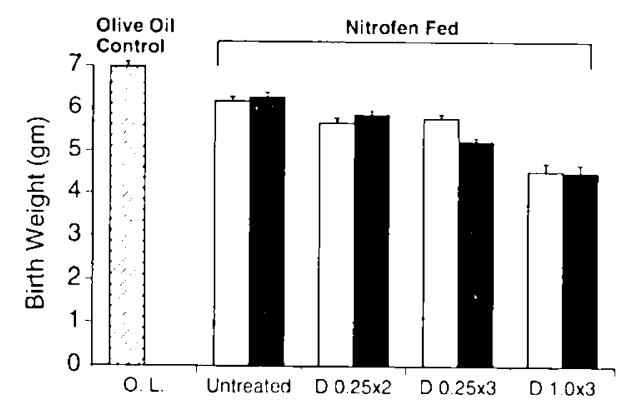

B

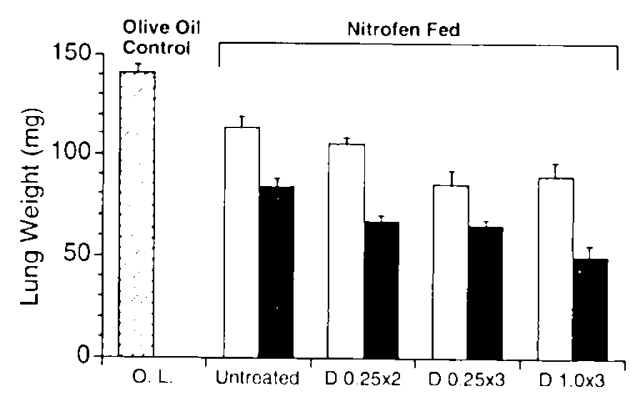

Fig. 3. Effects of antenatal dexamethasone on birth weight and lung weight. Antenatal dexamethasone decreased birth weight (A) and lung weight $(B)$ in a dose-dependent manner in both the $\mathrm{CDH}(\boldsymbol{\square})$ and non$\mathrm{CDH}$ rats $(\square)$. See Figure $2 A$ for number of animals represented by each bar. at the dose of $0.25 \mathrm{mg} / \mathrm{kg}$ on d 18.5 and 19.5 , only ETl gene expression (Fig. 7) showed a 1.8 -fold increase in the non-CDH rats $(p<0.001)$ and 2 -fold increase in the $\mathrm{CDH}$ rats $(p<0.001)$. The other differences after antenatal dexamethasone treatment were all less than $30 \%$ (Figs. 6 and 8 ). We observed no upregulation of SP-B mRNA in control animals fed olive oil (no nitrofen) and later treated with dexamethasone.

\section{DISCUSSION}

The observation that antenatal dexamethasone corrects the pulmonary immaturity in rats with large $\mathrm{CDH}$ indicates that antenatal glucocorticoid therapy might be efficacious in the treatment of human babies with severe $\mathrm{CDH}$. The incidence of $\mathrm{CDH}$ in the human population is approximately 1 in 3000 live births (39), leading, in the United States with 4 million live births, to approximately 1333 cases. The $60 \%$ mortality rate of $\mathrm{CDH}(40)$ would result in approximately 800 deaths a year, which is $25 \%$ of deaths caused by congenital heart disease in the $1 \mathrm{st} y$, or 1.3 times the deaths caused by leukemia from 0 to $14 \mathrm{y}$ $(41,42)$.

Pulmonary hypoplasia, persistent pulmonary hypertension, and surfactant deficiency are pathognomonic of severe and lethal CDH lungs. A similar pathophysiologic condition is found in the lungs of premature infants with hyaline membrane disease. Because antenatal glucocorticoid in premature babies has been proved to accelerate pulmonary maturity, thus reducing the incidence and severity of hyaline membrane disease and leading to improved survival, it is logical to consider the use of prenatal glucocorticoid therapy to accelerate pulmonary maturity in $\mathrm{CDH}$. We confirmed that nitrofen alone can suppress DSPC content in lung and reduces the birth weight and lung weight. However, we have shown that antenatal glucocorticoid treatment elevated the DSPC content and reduced the glycogen concentration compared with nitrofen-treated animals who received no dexamethasone and that DSPC improvement was more dramatic in the CDH lungs. Antenatal glucocorticoid treatment also reduced the saccular septal thickness and increased the saccular size and volume fraction of saccules in the lungs of rats with nitrofen-induced large CDH. Our observation that antenatal dexamethasone did not increase surfactant-associated protein mRNA levels in either nitrofen- or nonnitrofen-treated controls differs from results observed by others who reported increases of SP-A, SP-B, and SP-C mRNA levels in immature non-CDH lungs of rats treated with dexamethasone $(33,34)$. These differences may be the result of variations in dexamethasone dosage or timing of treatment. Further investigations by in situ hybridization and immunohistochemical localization may yield important cellular differences not appreciable by whole-lung extraction.

Antenatal glucocorticoid, when used to treat premature babies, is less effective when given after 34 wk gestation or if the baby is delivered more than $7 \mathrm{~d}$ after therapy $(14,15)$. Although most babies with $\mathrm{CDH}$ are full term, we predict that their lungs will respond to glucocorticoid because their lungs reflect the biochemical and morphologic patterns characteristic of prematurity $(9$, $10,13)$ and fall within the well-known window of responsiveness to glucocorticoid therapy.

Although glucocorticoid therapy in this study inhibited both somatic and pulmonary growth, long-term follow-up in other studies of both animals $(43)$ and human beings $(44,45)$ treated for prematurity alone detected no subsequent deleterious effects on somatic, pulmonary, psychologic, or intellectual development. Other salutory effects included a decreased incidence of patent ductus arteriosus (46), necrotizing enterocolitis (47), and intraventricular hemorrhage $(48,49)$, and stimulation of lung antioxidant enzymes (22).

Because antenatal glucocorticoid and postnatal surfactant replacement therapy have additive beneficial effects in the respiratory distress syndrome of prematurity $(50)$, the present study suggests that they may be similarly additive in neonates with 
A

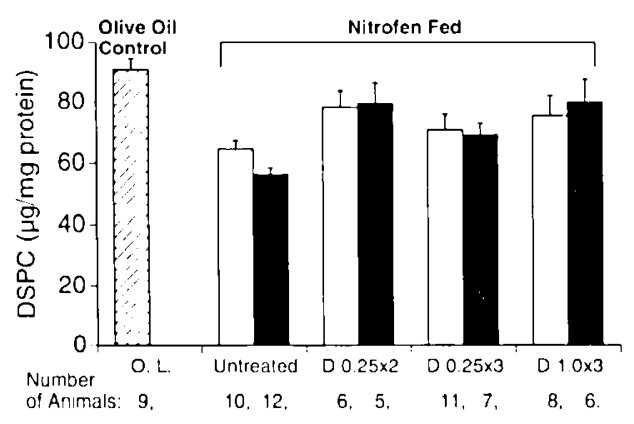

B

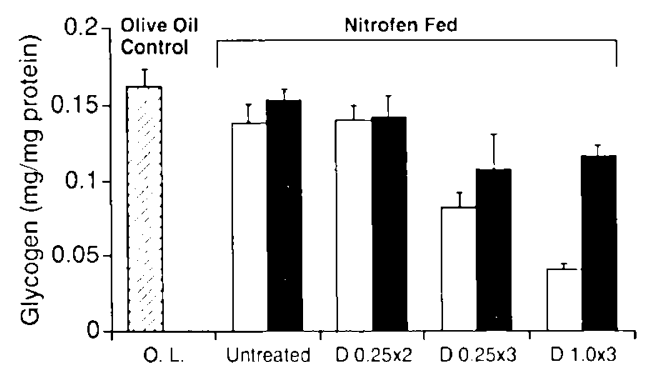

Fig. 2. Effects of antenatal dexamethasone on lung DSPC and glycogen. $1, \mathrm{CDH}$ rats and $\square$, non-CDH rats; $O . L$., rats whose mothers were fed olive oil only, without nitrofen: Untreated, not antenatally treated with dexamethasone; $D 0.25 \times 2,0.25 \mathrm{mg} / \mathrm{kg}$ dexamethasone i.p. on $\mathrm{d} 18.5$ and $19.5 ; D 0.25 \times 3,0.25 \mathrm{mg} / \mathrm{kg}$ dexamethasone i.p. on $\mathrm{d}$ $18.5,19.5$, and 20.5 ; and $D 1.0 \times 3,1 \mathrm{mg} / \mathrm{kg}$ dexamethasone i.p. on $\mathrm{d}$ 18.5, 19.5, and 20.5. A, Nitrofen treatment reduced the DSPC content in non-CDH lungs (lane 2 compared with lane 1 ). The presence of $\mathrm{CDH}$ (lane 3) further decreased DSPC content. Antenatal dexamethasone at the three doses tested corrected the DSPC levels toward normal. $B$, Lung glycogen concentrations were significantly reduced by higher doses of antenatal dexamethasone in both the nitrofen-treated $\mathrm{CDH}$ and non$\mathrm{CDH}$ rats. Without dexamethasone treatment (lanes 1,2, and 3), lung glycogen concentrations were similar in olive oil controls and in the nitrofen $\mathrm{CDH}$ and non-CDH lungs. The number of animals denoted in $A$ applies to $B$.

and a Dage-MTI model 65DX video camera (Michigan City, IN). The image was projected onto a Sony video monitor (Sony Corp., Tokyo, Japan). The randomized midcoronal sections of the right and left lungs were studied separately without knowledge of previous treatment. With right and left lungs counted separately, 18 lung sections from nine treated $\mathrm{CDH}$ rats were compared with 18 lung sections from nine untreated $\mathrm{CDH}$ rats and 16 lung sections from eight untreated non-CDH rats. Whenever possible, four fields on each lung section (randomly chosen from the superior, inferior, lateral, and medial aspects) were studied. In 11 of the 52 lung sections, only one to three fields were available for study because of pulmonary hypoplasia. A computer-generated grid containing 70 regularly spaced points, which had been previously calibrated with a $0.01-\mathrm{mm}$ micrometer, was superimposed on the lung image on the video monitor. With the help of a cursor, the length of all intercepts $\left(l_{0}\right)$ through test points overlying saccules were measured in a random direction, and the value of $\pi / 3 \cdot\left(\overline{l_{0}^{3}}\right)$ was used as an unbiased estimate of the mean saccular volume sampled $(30,31)$. An average of $82 l_{\circ}$ measurements were made for each lung section. The ratio of points intercepting saccules to the points overlying the lung parenchyma is in turn an objective estimate of the volume fraction of saccules in the lung (31).

Molecular analysis. Gene expression of surfactant-associated proteins SP-A, SP-B, SP-C, ET1, and endothelial nitric oxide synthase was measured with RNA blot hybridization or an
RNase protection assay. Three dams were treated with $0.25 \mathrm{mg} /$ $\mathrm{kg}$ dexamethasone i.p. on d 18.5 and 19.5, and two dams were saline injected on the same days. From these pregnancies, six dexamethasone-treated and six untreated $C D H$ rats were identified, and six treated and six untreated non-CDH rats were randomly chosen for analyses. Lungs harvested from these pups on 21.5 of gestation were immediately frozen in liquid nitrogen. RNA was extracted by the guanidine isothiocyanate/cesium chloride method (32). For RNA blot hybridization, 10- $\mu \mathrm{g}$ RNA samples were fractionated on a formaldehyde-agarose gel and transferred to a nitrocellulose membrane. The membrane was sequentially hybridized with ${ }^{32} \mathrm{P}$-labeled cDNA probes for SP-A, SP-B, and SP-C $(33,34)$. The membrane was hybridized with ${ }^{32}$ P-labeled $1-\mathrm{kb}$ Pst I restriction fragment of a cDNA encoding human glyceraldehyde-3-phosphate dehydrogenase to standardize the amount of RNA in each sample (35). The quantity of hybridizing probe bound to the membrane was measured with a Betascope 603 blot analyzer (Betagen Corp., Waltham, MA). The SD of loading as determined by the glyceraldehyde-3-phosphate dehydrogenase mRNA level in individual samples of specimen was $21 \%$. SP-B mRNA was similarly studied in nonnitrofen (olive oil)-treated controls with $(n=6)$ and without $(n=6)$ glucocorticoid treatment for comparison.

For RNase protection assay, RNA samples were incubated with radiolabeled antisense $\mathrm{CRNA}$ probes derived from restriction fragments of the rat ET1 gene (Bloch KD, unpublished observations) and of a partial rat endothelial nitric oxide synthase cDNA (Bloch KD, unpublished observation). For preparation of a uniformly labeled antisense ET1 cRNA probe, pGEM4-ET1 (containing exon 2) was linearized with EcoRI and incubated with T7 RNA polymerase in the presence of ${ }^{32} \mathrm{P}$-uridine triphosphate. A partial endothelial nitric oxide synthase cDNA was amplified from rat lung RNA with degenerate oligonucleotides corresponding to amino acids 1012 to 1018 and 1114 to 1120 of human endothelial nitric oxide synthase (36). An approximately $250 \mathrm{bp} \mathrm{BamHI/EcoRI} \mathrm{restriction} \mathrm{fragment} \mathrm{was} \mathrm{ligated} \mathrm{into}$ pGEM7zf. For preparation of a cRNA probe for rat endothelial nitric oxide synthase, the plasmid containing the partial cDNA was linearized with $\mathrm{Bam} \mathrm{HI}$ and incubated with T7 RNA polymerase. A radiolabeled antisense cRNA probe for human $\gamma$-actin (37) was added to each hybridization to confirm that equal concentrations of RNA were hybridized. RNA fragments protected from RNase were fractionated on a $6 \%$ urea-polyacrylamide gel. Hybridization of ET1 RNA probe with ET1 mRNA protected a predominantly 141-nucleotide radiolabeled fragment. Rat $\gamma$-actin mRNA protected an approximately 80-nucleotide fragment of human $\gamma$-actin probe. The quantity of protected probe was measured with the Betascope 603 blot analyzer. The SD of loading as determined by the $\gamma$-actin mRNA levels for the endothelin and the endothelial nitric oxide synthase experiments were $43 \%$ and $24 \%$, respectively.

Results were expressed as mean \pm SEM. Comparisons were analyzed statistically by analysis of variance, independent $t$ test, and post hoc testing; $p<0.05$ was statistically significant.

\section{RESULTS}

The DSPC content, which normally rises with maturity, was reduced significantly in the nitrofen non-CDH rats $(64.6 \pm 2.7$ $\mu \mathrm{g} / \mathrm{mg}$ protein) compared with the olive oil rats $(90.8 \pm 3.5 \mu \mathrm{g} /$ mg protein, $p<0.001)$. The presence of $\mathrm{CDH}$ further decreases the DSPC content $(56.3 \pm 2.2 \mu \mathrm{g} / \mathrm{mg}$ protein, $p=0.026 \mathrm{com}-$ pared with the nitrofen non- $\mathrm{CDH}$ rats). Among the $\mathrm{CDH}$ rats, the DSPC content was increased or partially corrected by dexamethasone at doses of $0.25 \mathrm{mg} / \mathrm{kg}$ i.p. for $2 \mathrm{~d}(79.5 \pm 6.8 \mu \mathrm{g} / \mathrm{mg}$ protein, $p=0.001)$ and for $3 \mathrm{~d}(69.1 \pm 3.8 \mu \mathrm{g} / \mathrm{mg}$ protein, $p=$ $0.037)$ and at doses of $1.0 \mathrm{mg} / \mathrm{kg}$ i.p. for $3 \mathrm{~d}(80.0 \pm 7.4 \mu \mathrm{g} / \mathrm{mg}$ protein, $p<0.001$ ) (Fig. 2A). A similar dexamethasone response was observed among the nitrofen non-CDH rats.

Lung glycogen mean concentrations normally fall coincident 

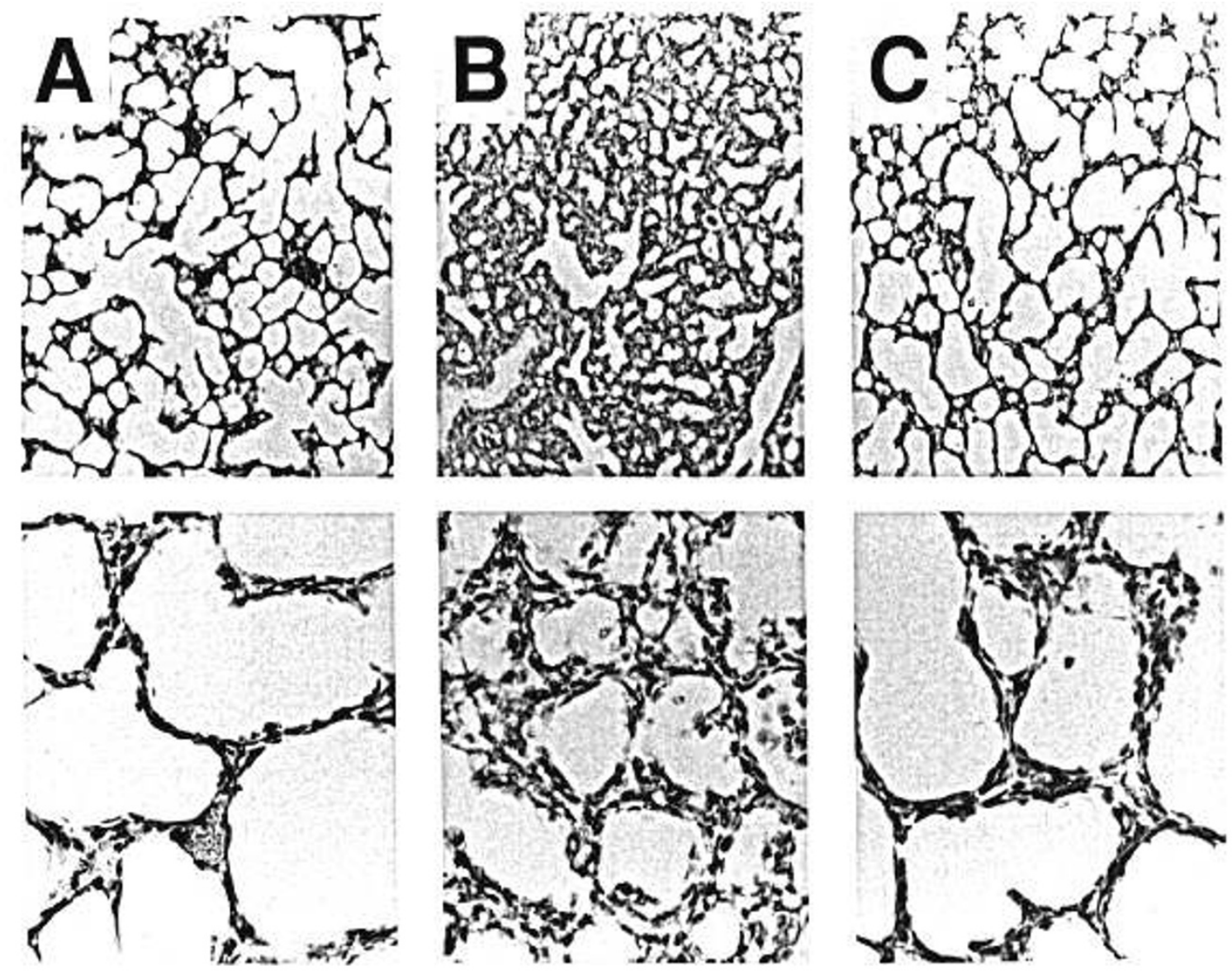

Fig. 4. Effects of antenatal dexamethasone on lung structure. (Top, magnification $\times 79 ;$ bottom, $\times 313)$. The untreated (DH lungs $(B)$ had small saccules and thick saccular septae compared with the treated $C D H$ lungs $(C)$ in which the histologic tissue, corrected by antenatal dexamethasone, resembled the untreated non-CDH lungs $(A)$.
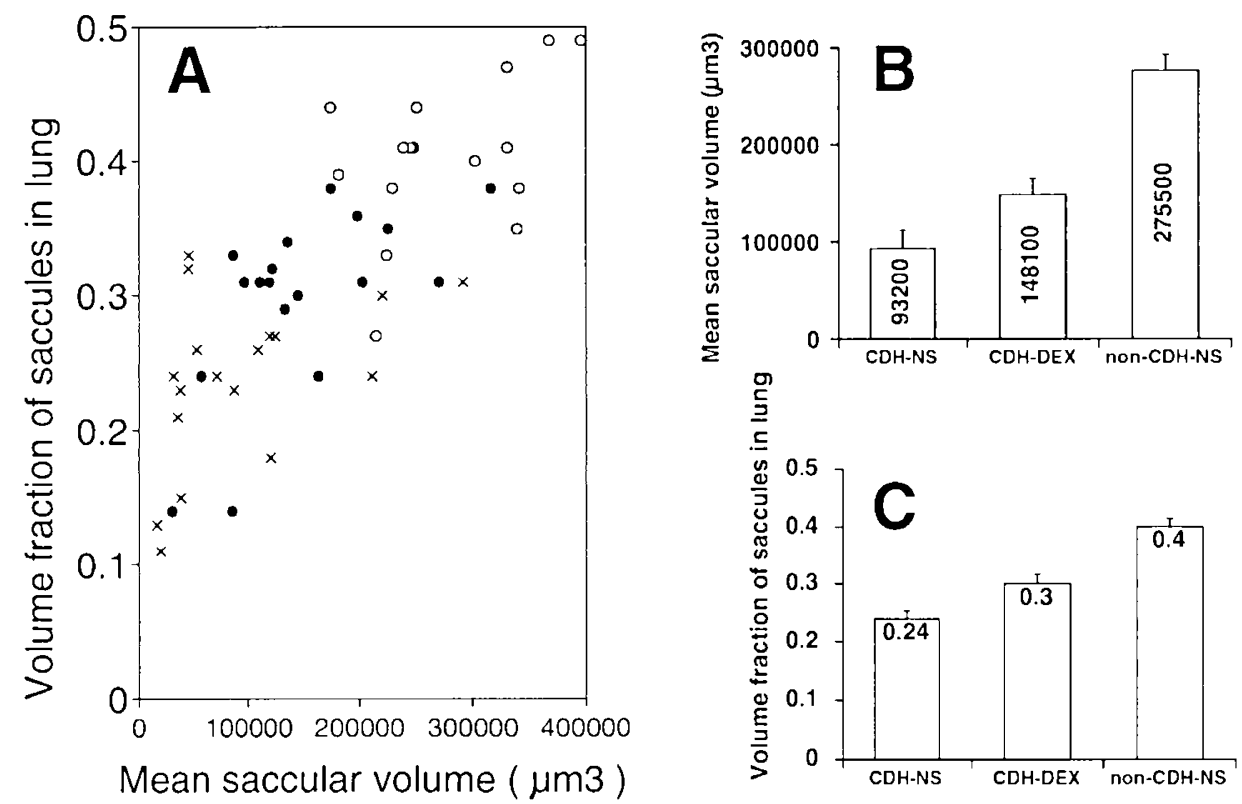

Fig. 5. Effects of antenatal dexamethasone on lung morphometry. A, All the individual data points from the stereologic study were shown. Despite scattering within each group, it can be appreciated that most of the dexamethasone-treated CDH values $(\bullet)$ fall between the untreated $\mathrm{CDH}$ values $(x)$ and the untreated non-CDH values $(O)$. B. The mean saccular volume of the untreated $C D H$ rats $(C D H-N S)$, which was much smaller than that of the untreated non-CDH rats (non-CDII-NS), was improved in the treated CDH rats $(C D H-D E X)$. $C$, The volume fraction of saccules in the lung of the untreated $C D H$ rats $(C D H-N S)$, which was much smaller than that of the untreated non-CDH rats (non-CDII-NS), was significantly improved in the treated $\mathrm{CDH}$ rats $(C D H-D E X)$. 


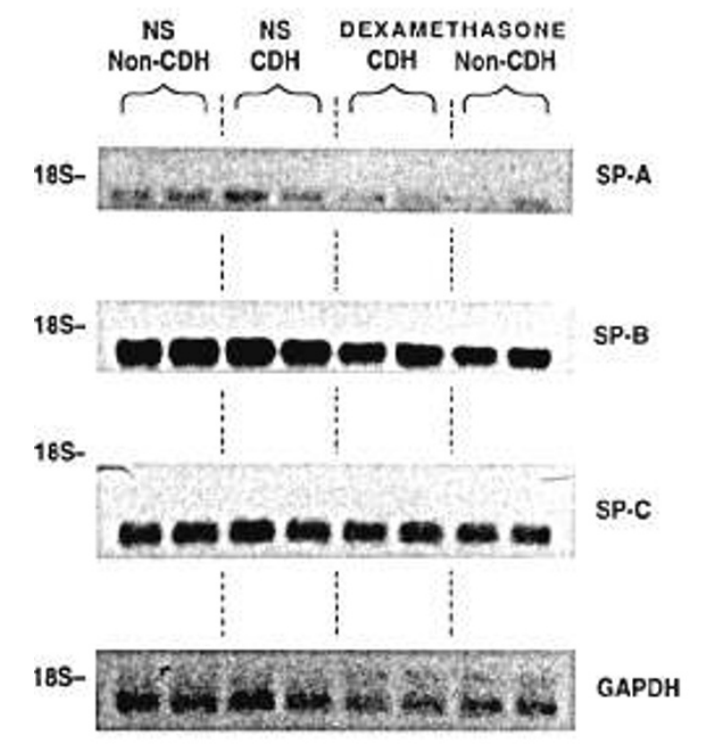

Fig. 6. Results of RNA blot hybridization showing pulmonary SP-A, SP-B, and SP-C mRNA levels in CDH and non-CDH rats with either antenatal saline $(N S)$ or dexamethasone treatment. Glyceraldehyde-3phosphate dehydrogenase mRNA level was used to standardize any differences in loading between samples. Position of $18 \mathrm{~S}$ rRNA is indicated.

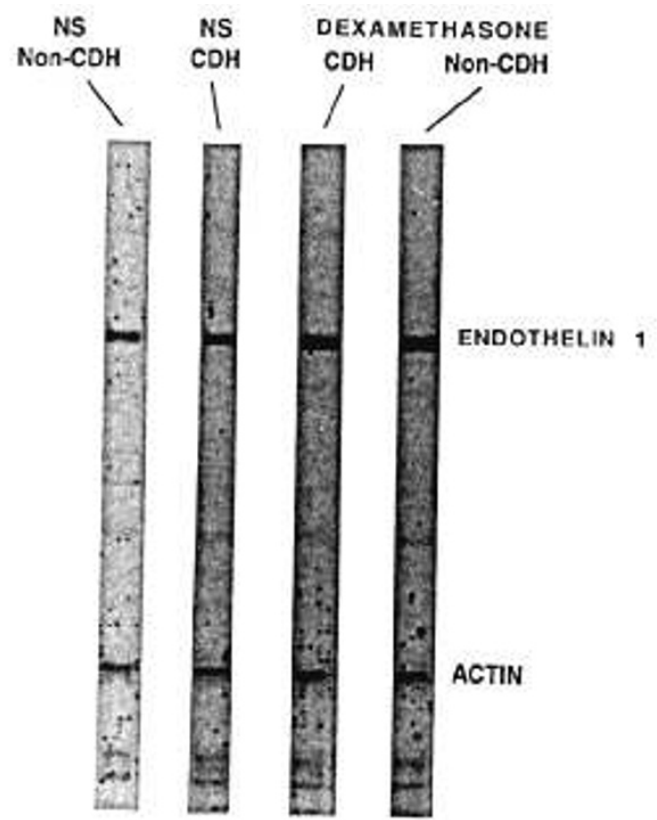

Fig. 7. Representative results of RNase protection assay showing no change in pulmonary endothelin $1 \mathrm{mRNA}$ level between untreated $\mathrm{CDH}$ and non-CDH rats. There was, however, a 1.8 -fold increase in the non$\mathrm{CDH}$ rats $(p<0.001)$ and 2 -fold increase in the CDH rats $(p<0.001)$ after antenatal dexamethasone treatment. $N S$, normal saline.

prenatally diagnosed $\mathrm{CDH}$. Antenatal ultrasonography can visualize these defects, and cases exhibiting criteria indicative of a near $100 \%$ mortality rate can be predicted with accuracy $(1,2)$; therefore, treatment of these babies with an established agent such as antenatal glucocorticoid should be considered as a therapeutic option after confirmation of the present observations in larger animal models with surgically created $\mathrm{CDH}$ without the use of nitrofen. When appropriate, antenatal glucocorticoid treatment should be compared or combined with surfactant replacement therapy (51), extracorporeal membrane oxygenation (52), or nitric oxide inhalation therapy (53) in the treatment of babies with severe $\mathrm{CDH}$.

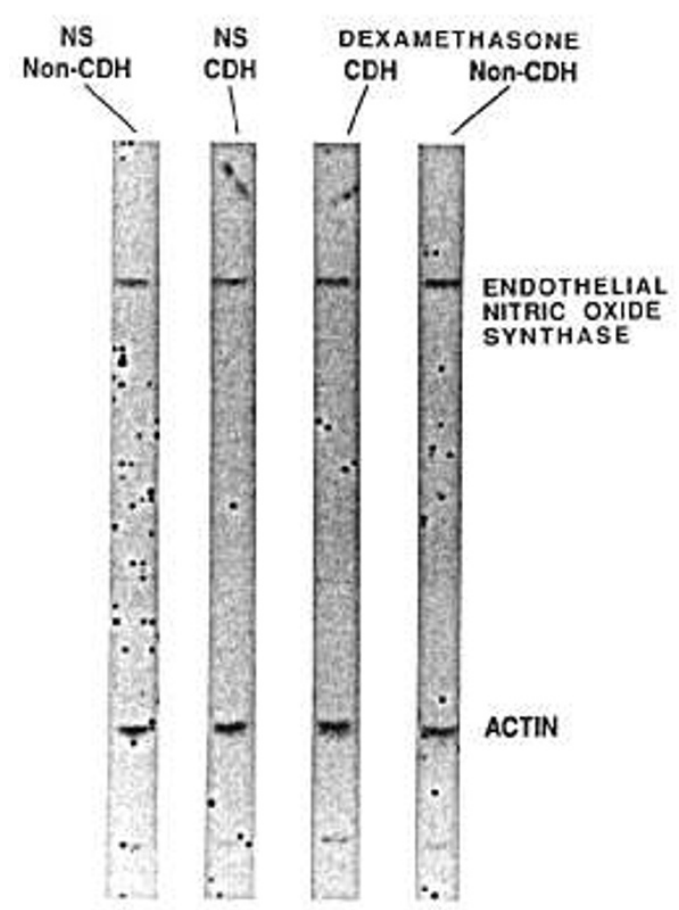

Fig. 8. Representative results of RNase protection assay showing no change in pulmonary endothelial nitric oxide synthase mRNA level between untreated $\mathrm{CDH}$ and non-CDH rats or between untreated and dexamethasone treated $\mathrm{CDH}$ and non-CDH rats. $N S$, normal saline.

Acknowledgments. The authors thank Joanna Floros of the Department of Cellular and Molecular Physiology, Milton S. Hershey Medical Center, Hershey, PA, for the kind gift of SP-A, SP-B, and SP-C probes; Maria Alexander of the Medical Services and Diabetes Unit, Massachusetts General Hospital, Boston, $\mathrm{MA}$, for the kind gift of GAPDH probe; Randolph Byers of the Department of Dermatopathology, Massachusetts General Hospital, Boston, MA, for generously providing guidance and access to imaging analysis; Gallina Filibbov of the Cardiovascular Research Laboratory, Department of Medicine, for assistance with Northern analysis; Warren M. Zapol of the Department of Anesthesia, Daniel P. Doody, Daniel P. Ryan, Jay J. Schnitzer, and Paul Losty of the Pediatric Surgical Services, Massachusetts General Hospital, Boston, MA, for critical discussion, advice, and assistance.

\section{REFERENCES}

1. Adzick NS, Harrison MR, Glick PL, Nakayama DK, Manning FA, deLorimier AA 1985 Diaphragmatic hernia in the fetus: prenatal diagnosis and outcome in 94 cases. J Pediatr Surg 20:357-361

2. Adzick NS, Vacanti JP, Lillehei MR 1989 Fetal diaphragmatic hernia: ultrasound diagnosis and clinical outcome in 38 cases. J Pediatr Surg 24:654-
658

3. Areechon W, Reid L 1963 Hypoplasia of lung with congenital diaphragmatic hernia. BMJ 1:230-233

4. Kitagawa M. Hislop A, Boyden EA, Reid L 1971 Lung hypoplasia in congenital diaphragmatic hernia. Br J Surg 58:342-346

5. Nguyen L, Guttman FM. De-Chadarevian JP, Beardmore HE, Karn GM Owen HF, Murphy DR 1983 The mortality of congenital diaphragmatic hernia. Is total pulmonary mass inadequate, no matter what? Ann Surg 198:766-770

6. Geggel RL, Murphy JD, Langleben D, Crone RK, Vacanti JP, Reid LM 1985 Congenital diaphragmatic hernia: arterial structural changes and persistent pulmonary hypertension after surgical repair. J Pediatr 107:457-464

7. Blackburn WR, Logsdon P. Alexander JA 1977 Congenital diaphragmatic hernia: studies of lung composition and structure. Am Rev Respir Dis 115(suppl):275(abstr)

8. Wigglesworth JS, Desai R, Guerrini P 1981 Fetal lung hypoplasia: biochemical and structural variations and their possible significance. Arch Dis Child 56:606-615

9. Berk C. Grundy M 1982 "High risk" lecithin/sphingomyelin ratios associated with neonatal diaphragmatic hernia. Case reports. Br J Obstet Gynecol $89: 250-251$

10. Hisanaga S, Shimokawa H, Kashiwabara Y 1984 Unexpectedly low lecithin/ 
sphingomyelin ratio associated with fetal diaphragmatic hernia. Am J Obstet Gynecol 149:905-906

11. Bell MJ, Ternberg JL 1977 Antenatal diagnosis of diaphragmatic hernia. Pediatrics 60:738-740

12. Kamata S. Hasegawa T, Matsuo Y, Fukuzawa M. Imura K, Okada A 1992 Fetal diaphragmatic hernia: prenatal evaluation of lung hypoplasia and effects of immediate operation. Pediatr Surg Int 7:109-112

13. George DK. Cooney TP, Chiu BK. Thurlbeck WM 1987 Hypoplasia and immaturity of the terminal lung unit (acinus) in congenital diaphragmatic hernia. Am Rev Respir Dis 136:947-950

14. Liggins GC. Howie RN 1972 A controlled trial of antenatal glucocorticoid treatment for prevention of the respiratory distress syndrome in premature infants. Pediatrics 50:515-525

15. Collaborative Group on Antenatal Steroid Therapy 1981 Effect of antenatal dexamethasone administration on the prevention of respiratory distress syndrome. Am J Obstet Gynecol 141:276-287

16. deLemos RA, Shermeta DW, Knelson JH, Kotas R, Avery ME 1970 Acceleration of appearance of pulmonary surfactant in the fetal lamb by administration of corticosteroids. Am Rev Respir Dis 102:459-461

17. Kotas RV. Avery ME 1971 Accelerated appearance of pulmonary surfactant in the fetal rabbit. J Appl Physiol 30:358-361

18. Wang NS, Kotas RV, Avery ME, Thurlbeck WM 1971 Accelerated appearance of osmiophilic bodies in fetal lungs following steroid injection. J Appl Physiol 30:362-365

19. Massaro D. Massaro GD 1986 Dexamethasone accelerates postnatal alveolar wall thinning and alters wall composition. Am J Physiol 251:R218-R224

20. Johnson JWC, Mitzner W, London WT, Palmer AE, Scott R 1979 Betamethasone and the rhesus fetus: multisystemic effects. Am J Obstet Gynecol 133:677-684

21. Mitzner W, Johnson JWC, Scott R, London WT, Palmer AE 1979 Effect of betamethasone on pressure-volume relationship of fetal rhesus monkey lung. J Appl Physiol 47:377-392

22. Frank L, Lewis PL, Sosenko RS 1985 Dexamethasone stimulation of fetal rat lung antioxidant enzyme activity in parallel with surfactant stimulation. Pediatrics 75:569-574

23. Suen HC, Catlin EA, Ryan DP, Wain JC, Donahoe PK 1993 Biochemical immaturity of lungs in congenital diaphragmatic hernia. J Pediatr Surg 28:471-477

24. Massaro GD, Clerch L, Massaro D 1986 Perinatal anatomic development of alveolar type II cells in rats. Am J Physiol 20:R470-R475

25. Folch J, Lees M, Sloane-Stanley GH 1957 A simple method for the isolation and purification of total lipids from animal tissues. J Biol Chem 226:497509

26. Mason RJ. Nellenbogen J, Clements JA 1976 Isolation of disaturated phosphatidylcholine with osmium tetroxide. J Lipid Res 17:281-284

27. Bartlett GR 1959 Phosphorus assay in column chromatography. J Biol Chem 234:466-468

28. Lo S. Russell JC. Taylor AW 1970 Determination of glycogen in small tissue samples. J Appl Physiol 28:234-236

29. Bradford MM $1976 \mathrm{~A}$ rapid and sensitive method for the quantitation of microgram quantities of protein utilizing the principle of protein-dye binding. Anal Biochem 72:248-254

30. Gundersen HJG, Jensen EB 1985 Stereological estimation of the volumeweighted mean volume of arbitrary particles observed on random sections. J Microscopy 138:127-142

31. Nielsen K, Colstrup H, Nilsson T, Gundersen HJG 1986 Stereological estimates of nuclear volume correlated with histopathological grading and prognosis of bladder tumour. Virchows Arch B Cell Pathol 52:41-54

32. Sambrook J, Fritsch EF, Maniatis T 1989 Molecular Cloning. A Laboratory
Manual. Cold Spring Harbor Laboratory Press, Cold Spring Harbor, NY, pp 7.19-7.22

33. Phelps DS, Floros J 1991 Dexamethasone in vivo raises surfactant protein B mRNA in alveolar and bronchiolar epithelium. Am J Physiol 260:L161-167

34. Schellhase DE, Shannon JM 1991 Effects of maternal dexamethasone on expression of SP-A, SP-B, and SP.C in the fetal rat lung. Am J Respir Cell Mol Biol 4:304-312

35. Ercolan L, Florence B. Denaro M. Alexander M 1988 Isolation and complete sequence of a functional human glyceraldehyde-3-phosphate dehydrogenase gene. J Biol Chem 263:15335-1534!

36. Janssens SP, Shimouchi A, Quertermous T, Bloch DB, Bloch KD 1992 Cloning and expression of a cDNA encoding human endothelium-derived relaxing factor/nitric oxide synthase. J Biol Chem 267:14519-14522

37. Enoch T, Zinn K, Maniatis T 1986 Activation of the human beta-interferon gene requires an interferon-inducible factor. Mol Cell Biol 6:801-810

38. Rooney SA, Gobran LI, Chu AJ 1986 Thyroid hormone opposes some glucocorticoid effects on glycogen content and lipid synthesis in developing fetal rat lung. Pediatr Res 20:545-550

39. Puri P Gorman WA 1987 Natural history of congenital diaphragmatic hernia: implications for management. Pediatr Surg Int 2:327-330

40. Harrison MR, Bjordal RI, Langmark F, Knutrud O 1978 Congenital diaphragmatic hernia: the hidden mortality. J Pediatr Surg 13:227-230

41. World Health Organization 1990 World Health Statistics Annual 1990. WHO. Geneva, pp 166-169

42. Pringle KC 1991 Fetal surgery: practical considerations and current status: where do we go from here with Bochdalek diaphragmatic hernia? In: Fallis JC, Filler RM, Lemoine G (eds) Pediatric Thoracic Surgery. Elsevier, New York, pp 333-342

43. Kotas RV, Mims LC, Hart LK 1974 Reversible inhibition of lung cell number after glucocorticoid injection into fetal rabbits to enhance surfactant appearance. Pediatrics 53:358-361

44. Howie RN, Liggins GC 1982 The New Zealand study of antepartum glucocorticoid treatment. In: Farrell PM (ed) Lung Development: Biological and Clinical Perspectives. Academic Press, New York, pp 255-273

45. Collaborative Group on Antenatal Steroid Therapy 1984 Effects of antenatal dexamethasone administration in the infants: long term follow-up. J Pediatr 104:259-267

46. Clyman RI, Ballard PL, Sniderman S, Ballard RA, Roth R, Heymann MA, Granberg JP 1981 Prenatal administration of betamethasone for prevention of patent ductus arteriosus. J Pediatr 98:123-128

47. Bauer CR, Morrison JC, Poole WK, Korones SB, Boehm JJ, Rigatto H Zachman RD 1984 A decreased incidence of necrotizing enterocolitis after prenatal glucocorticoid therapy. Pediatrics 73:682-688

48. Ballard RA. Ballard PL, Granberg JP, Sniderman S 1979 Prenatal administration of betamethasone for prevention of respiratory distress syndrome. J Pediatr 94:97-101

49. Tacusch HW, Frigoletto F, Kitzmiller J. Avery MA. Hehre A, Fromm B, Lawson E, Neff RK 1979 Risk of respiratory discase syndrome after prenatal dexamethasone treatment. Pediatrics 63:64-72

50. Kresch MJ, Gross I 1987 The biochemistry of fetal lung development. Clin Perinatol 14:481-507

51. Bos AP, Tibboel D, Hazebroek FW. Molenaar JC, Lachmann B, Gommers D 1991 Surfactant replacement therapy in high-risk congenital diaphragmatic hernia (letter). Lancet 338:1279

52. Wilson JM, Lund DP, Lillehei CW, Vacanti JP 1991 Congenital diaphragmatic hernia: predictors of severity in the ECMO area. J Pediatr Surg 26:10231027

53. Roberts JD, Polaner DM, Lang P. Zapol WM 1992 Inhaled nitric oxide in persistent pulmonary hypertension of the newborn. Lancet 340:818-819 